\title{
A Case of Online Teaching and Learning during COVID-19 in Medical Laboratory Science Education and Training in Federal School of Medical Laboratory Science, Jos.
}

\author{
Obeta, M.U. ${ }^{1,4}$, Etukudoh, N.S. ${ }^{2}$, Ejinaka, R.O. ${ }^{3}$.
}

\begin{abstract}
Online teaching and learning in medical laboratory science have been neglected over the years. The current situation of COVID-19 pandemic is an eye opener to encourage online learning in medical laboratory science considering the lock down for more than seven months in Nigeria and other parts of the world in medical laboratory training and education using the conventional classroom and face to face teaching and mentoring. The possible online teaching and learning platforms are Google duo, Webex Meet, Canvas Student, Skype, WhatsApp, Hangouts, Google meeting, Google classroom, GoToMeeting, Microsoft Teams and Zoom. The medical laboratory science or other medical science education institutions or regulatory agencies may choose two or three platforms from the list or develop another App to suit their curriculum. This article takes a close look at online learning in relation to medical laboratory science towards encouraging the training institutions and regulatory agencies of the profession for another look at online teaching learning for medical laboratory science as Federal School of Medical Laboratory Science, Jos-Nigeria commences online learning programme using WhatsApp and Zoom during the coronavirus period. It is evident that online teaching and learning is on the increase since the onset of coronavirus pandemic in Nigeria and in Federal School of Medical Laboratory Science, Jos in particular.
\end{abstract}

Keywords: Online teaching and learning, Medical laboratory science, coronavirus, COVID-19

\section{Introduction}

Medical laboratory science also called Clinical laboratory science depending on the country of practice (Obeta et al, 2020a) is a profession in medical science that involve the "analysis of human or animal tissues, body fluids, excretions, production of biologicals, designs and fabrication of equipment for the purpose of medical laboratory testing, treatment and research" (Obeta et al, 2019).

Medical laboratory science is practical based profession during training and practice and

${ }^{1}$ Department of Medical Laboratory Management, Federal School of Medical Laboratory Science, Jos-Nigeria

${ }^{2}$ Office of the Provost/CEO, Federal School of Medical Laboratory Science, Jos-Nigeria

${ }^{3}$ Office of the Deputy Provost Academics, Federal School of Medical Laboratory Science, Jos-Nigeria

${ }^{4}$ Department of Public Administration and Local Government, University of Nigeria, Nsukka-Nigeria

Corresponding Author: Obeta Uchejeso, Department of Medical Laboratory Management, Federal School of Medical Laboratory Science, Jos-Nigeria.

Email: uchejesoobeta@gmail.com

DOI: http://doi.org/10.4038/seajme.v14i2.277 needs improvement especially during the COVID-19 (Obeta et al, 2020b, Etukudoh et al, 2020). The advent of $21^{\text {st }}$ century serves as a digital learning era around the world. Computers are immensely and increasingly used in all aspect of learning including the medical laboratory science. E-learning encouraged the use of computer technology which makes it users' friendly especially medical laboratory scientists in training or practice to access all format and make it reliable and reusable.

E-learning refers to the use of computer-based technologies for the impartation of knowledge on healthcare education which can be delivered without the physical contact among learners. Such learning may cover many areas including tele-education, tele-health, e-health, and telemedicine. Telephone lines are used by transmission of digitalised signals with modem, satellites, optical fiber and various technologies. The information communication technologies (ICT) can be used for continuous professional development and education for the health systems, medical laboratory science inclusive. Kimberly et al, (2004) has identified online teaching and learning as veritable tool towards educational improvement. O'Doherty 
and colleagues described e-learning as "electronic or online learning can be used of electronic technology and media to deliver, support and enhance both learning and teaching and involves communication between learners and teachers utilizing online content. Online learning can provide students with easier and more effective access to a wider variety and greater quantity of information" (O'Doherty et al, 2018).

\section{Online Teaching and E-learning in Perspective}

Online teaching and e-learning employs the use of computer and other digital technologies to deliver education and training thereby enabling learning and improvement of performance among the students or trainees. It is a means of communication which is done via online settings. Electronic learning which is shorten for e-learning is the fastest and easiest means of learning that has been in existence for many years with everyday technological innovations and development that makes it reliable. It is facilitated through ICT.

Terms in e-learning include; video teleconferencing (VTC), stimulator-based learning, mobile learning, mediated learning, internet-based learning /web-based learning / online learning /virtual learning, e-teaching, distance learning/digital library, computerbased training, blended learning (Frehywort et al, 2013). E-learning employs a pedagogical approach providing a flexible, supportive and self-paced learning environment (Bodhare, 2020).

Computers stores information to the extent that such information can be retrieved from the system or online through internet. The computers enable reproduction of accurate information time after time. Appropriate use and internet connections aids knowledge transfer from the lecturers to the students. Recently the computers have helped some resourceful books or textbooks to be turned into e-textbook and stored in various systems or websites to the extent that any written page of such books can be viewed on the computer screen depending on the need (Choules, 2007).

Various institutions are bound to develop their online teaching platforms based on the learning objectives and curriculum of study, medical laboratory science for example. Such programs are delivered using different online compatible systems and presented as texts, audio, graphics, and video based on the choice and need. The medium in use should provide as much learning support as possible. There is need for a thorough explanations, provision of examples, interaction activities, possible feedbacks, and glossaries information while making learners to be self-sufficient. In addition, there should be provision for support using email technical support or e-tutoring that is provided to learners. In self-paced online training and e-learning, there is an important need to track learners' actions using a central database. These attributes of e-learning could be employed in medical laboratory science for better outcome.

Online/ e-learning components in line with FAO, (2011) includes;

\section{Online teaching and e-learning content}

a. Simple learning resources: These are found in non-interactive resources learning platforms. Examples are videos, audios, documents, Power Point presentations and files. These resources can easily and quickly be developed. They should be made to match the defined learning objectives such as medical laboratory science courses. They are designed in a structured way in line with curriculum. They can be a valuable learning resources but do not provide any interactivity between the lecturer and the student.

b. Interactive e-lessons: These are common approach employed for self-paced e-learning. It is referred to as Web-based training which consist of a set of interactive e-lessons. Examples are; texts, audios, videos, graphics, and animations. The interactivity is seen in the form of questions and feedback between the teacher and the learner. It can also include recommended reading and links to online resources, as well as additional information on specific topics depending on the course work.

c. Electronic stimulator: These are highly interactive forms of online and e-learning. It creates a learning environment that "simulates" the real world situation. It allows the learner or the student to learn by doing some activities included by the lecturer or trainer based on the course and Web-based training in use for such course.

d. Job aids: These provide just-in-time knowledge in several forms and be delivered on different platforms. The example of job aids could be seen in computer, printed document, and mobile phones. They can provide immediate answers to specific questions, thus helping users accomplish job tasks. Technical 
glossaries and checklists are a few examples of simple job aids, but sophisticated expert systems can also be developed to assist workers in complex course-learning environment like the medical laboratory science.

2. E-tutoring, e-lecturing, e-mentoring, ecoaching are part of the components that provides human and social dimension. They can be offered to students or trainees or learners as a support to the learning experience based on who is involved and method of approach.

3. Collaborative learning is the component that range from discussions and knowledge sharing to working together on a common project. Social software such as chats, discussion forum and blogs are used for such online collaboration among students and learners.

4. Virtual Classroom is the instructural component that is mostly similar to traditional classroom teaching and training. This is led completely by the teacher or the instructor.

Online teaching and e-learning activities can be synchronous and asynchronous. Synchronous learning or event takes place in real time. Synchronous communication between two people require them to both be present at a given time e.g chats, live web casting, white board, application sharing, audio/video conferencing, and polling. Synchronous online learning is seen in Zoom e-learning platforms.

Asynchronous events are time independent and not the real time event. A self-paced course is an example of asynchronous e-learning because online learning takes place at any time as seen in e-mail, discussion forum, wiki, blog and most asynchronous are seen in YouTube, and Google classrooms.

FAO (2011) described how quality of e-learning can be enhanced and such is needed in medical laboratory science:

Learner-centred content: Online curricula should be relevant and specific to learners' needs, roles and responsibilities to provide skills, knowledge and information in medical laboratory science profession.

Granularity: Online content should be segmented to facilitate assimilation of new knowledge. The scheduling should be flexible for learning the theories and practical aspect of the profession.
$>$ Engaging content: Instructional methods and techniques should be used creatively to develop an engaging and motivating medical laboratory science learning experience.

$>$ Interactivity: Frequent learner interaction is needed to sustain attention and promote learning both in theories and practical courses such as medical laboratory science.

> Personalization: Self-paced courses should be customizable to reflect learners' interests and needs; in instructor-led courses, tutors and facilitators should be able to follow the learners' progress and performance individually. This calls for further personal interaction inform of assignments and feedback follow up.

\section{Possible Online Learning and Teaching Platforms for Medical Laboratory Education}

Various platforms for e-learning for the medical laboratory science are available and easy to access based on the type of lecture either practical or theoretical. The possible e-learning platforms that can be used in medical laboratory science education may include: Google duo, Webex Meet, Canvas Student, Skype, WhatsApp, Hangouts, Google meeting, Google classroom, Google Meet, GoToMeeting, Microsoft Teams and Zoom. The world wide web serves as the major server for e-learning that can be employed in medical laboratory science which gives a platform for easy flow of information at a minimum time (Obeta eta al, 2020c, Omoregbe et al, 2015). While WhatsApp can carry only 256 persons at a time, Zoom may support up to 11,000 students per lecture (Dias, 2020) and can be employed in the training of large number of students at a time.

There is no doubt that access to internet, technical expertise, information authentication and monitoring of quality responses from learners (Shrivastava and Shrivastava, 2019) could be the limitations of possible learning platforms in medical laboratory science but resources sharing, cost effectiveness, convenience and steady pace in usage of the platforms should encourage the e-learning education in medical laboratory science education.

The online teaching platforms specifically made for medical laboratory science do not exist 
anywhere. It is dependent on the institution and their teaching curriculum to choose from numerous platforms as enumerated above and adapt anyone or two to suit their need. In Federal school as an institution, both lecturers and students uses WhatsApp, but after the COVID-19 pandemic index case in Nigeria by Federal Ministry of Health (FMOH, 2020), the institution adapted it for use in the interim for online learning until the virtual platform (Zoom) is fully in use. With this numerous list of online / e-learning platforms, there should be no profession that would complain of not learning as at when needed due to pandemic or what so ever as the rise in online learning has also increased the number of such online Apps.

\section{Possibility of Online Learning in Medical Laboratory Science}

Online teaching and e-learning development is ongoing across the globe. The online technologies available in medical science has the ability to relate healthcare professionals among the healthcare team including patients. There are possibilities of the use of online teaching and e-learning in medical Laboratory science in terms of equipment installation, molecular diagnostic procedures and other medical laboratory testing procedures. Colleagues in specialized areas of medical and hospitals practice can transmit instructions from a far distance for the purpose of solving medical problems among certain cadres using either synchronous and asynchronous communications or inform of pictorial and other records (O'Doherty et al, 2028).

Moreover, a medical scientist can communicate with a patient via email and sends results and data of a patient when test are done. ICT has provided the possibilities for health professionals to exchange knowledge and findings using any available platforms in healthcare. Though the applications and usage are still far from a level actually deserved in medical laboratory science. The emergence of coronavirus challenged medical laboratory professionals especially in Nigeria for more knowledge which was gotten through online learning. Those that lacked computing skills among Medical laboratory professionals and other health workers were left with no option than to collaborate with those with proficient computer skills in various hospitals. Various trainings carried out by Nigerian Center for Disease Control and other National and International organizations were done either online or virtual training with regards to coronavirus sample collection and molecular techniques (Figure 1). Technical possibilities for faster e-learning development is already in existence and organizational infrastructural solutions are yet to be developed which will enhance information technology (IT) literacy among medical laboratory science professionals.

From our experience in Federal School of Medical Laboratory Science, Jos as a case study, the online teaching and learning in medical laboratory science is very possible. Federal School of medical laboratory science, Jos has existed for more than 60 years without any record on online teaching or e-learning. The management of the college through a memo released on $27^{\text {th }}$ March, 2020 mandated all the lecturers to plan towards online teaching and a similar memo to students to get ready for e-learning. Subsequently, the management conducted a survey among the lecturers and students on the best approach to commence online teaching and e-learning. The options in the mind of the management was for synchronous online teaching and learning platform with the aid of Zoom App rather than asynchronous learning platform using WhatsApp.

From the survey, $50 \%$ of the lecturers do not have Zoom App or do not have the device that can use the App effectively while $75 \%$ of the students do not have the App or the device that can effectively use the App. On the other hand, $100 \%$ of the Lecturers had WhatsApp App on their Android phones while $96 \%$ of the students had the WhatsApp App in their phones.

Following the outcome of the survey, the management through the Office of the Deputy Provost Academics, therefore, released a memo that reads "I am directed by the Deputy Provost Academics that our online lectures will commence on $20 / 04 / 2020$ by 9 am. By this notice, all lecturers are directed to send in their e-lecture notes(s) to a provided e-mail by 19/04/2020. A new timetable (Figure 2), will be communicated to all lecturers within 48 hours from now. All arrangement has been concluded on how the e-learning will operate, lecture notes will be uploaded to the students WhatsApp platform prior to the online lecture by the lecturers until all staff and students have migrated to Zoom. This lead to creation of Class WhatsApp groups as managed by an ICT officer. The platform was made to function as synchronous platform where lecturer and students are present at a given time in the group for lecture. The students are instructed to indicate their presence (Figure 3 ) at the 
beginning and the end of the lectures in a bid to monitor attrition associated with online teaching and learning. The Lecturers present their lectures as Texts, Voice messages (Figure 4) and short recorded videos especially for practical demonstrations.

The online learning created fast learning, covering of curriculum within the expected time and adequate convenience to lecturers and students while staying safe at home during the coronavirus pandemic. Though some challenges such as power failure insufficient data and poor internet access has been the major set back. The experience in the online learning as observed in Federal School of Medical Laboratory Science Jos agrees with positions of Holmes and Reid (2017), AlQahtani (2019) Murillo et al, 2020, Izet (2008), and Bao (2020) in the area of perspectives of online/virtual learning, advantages and disadvantages, improvements in outcome both in lecturers and students.

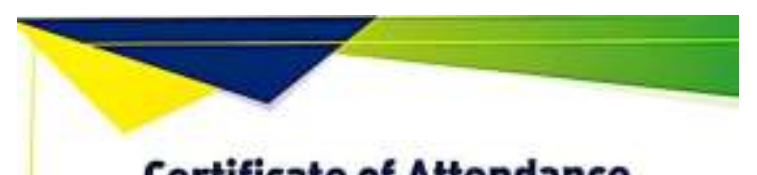

\section{Certificate of Attendance}

\section{elesmilyou}

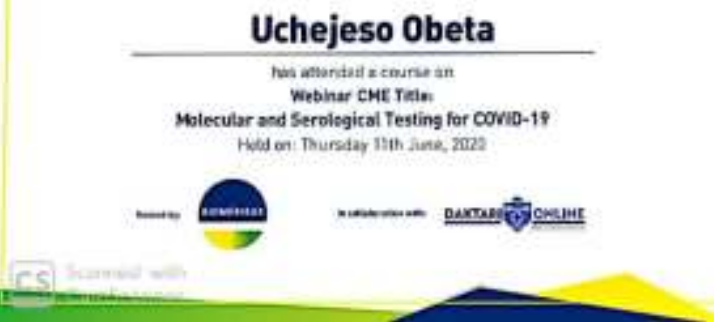

Figure 1: E-Learning Certificate by a medical Laboratory Scientist

\begin{tabular}{|c|c|c|c|}
\hline COURSE & DAYs & Tin & at: \\
\hline MLT $202 / 302$ & MONDAY & Vam-11am & {$[12 p m-2 p m$} \\
\hline MLT 206/a06 & TUESDAY & 9am-11am & $12 p m-2 p m$ \\
\hline $\begin{array}{l}\text { MLT 216 } \\
\text { MLT 212 } \\
\text { MLT 210 }\end{array}$ & WEDNESDAY & $\begin{array}{c}9 \mathrm{am}-17 \mathrm{~mm} \\
12 \mathrm{pm}-2 \mathrm{gm} \\
3 \mathrm{pm}- \\
4.0 \mathrm{pm}\end{array}$ & - \\
\hline $\begin{array}{l}\text { MLT 204/304 } \\
\text { MLT } 310\end{array}$ & THURSDAY & 9um - 17am & $\begin{array}{l}17 p m-2 p m \\
3 p e n- \\
430 p m\end{array}$ \\
\hline MLT 200/300 & FRIDAY & 6 am-11am & $12 p m-2 p m$ \\
\hline
\end{tabular}

Figure 2: FSMLS E-Learning Time Table during COVID-19 Lockdown in Jos Nigeria 


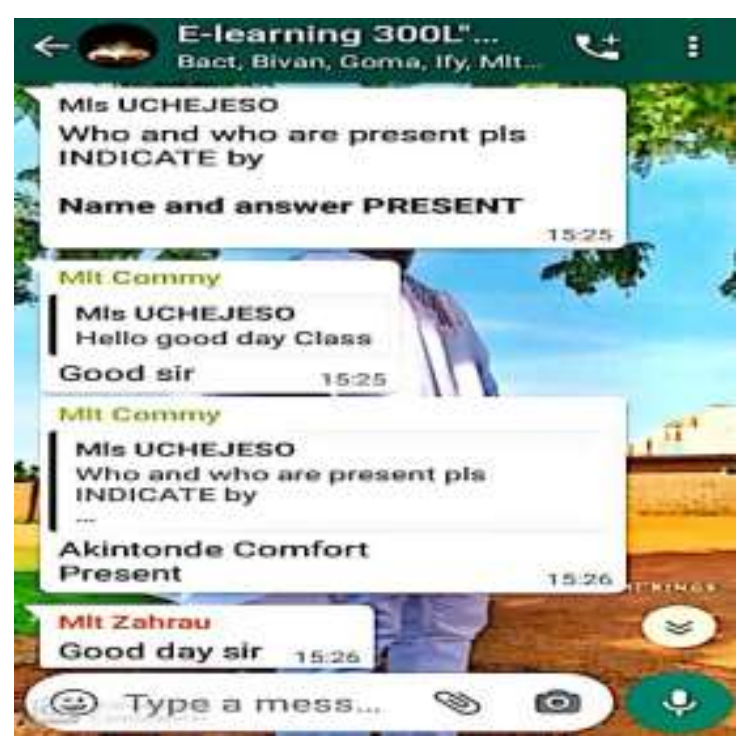

Figure 3. E-learning Attendance for FSMLS 300L Students

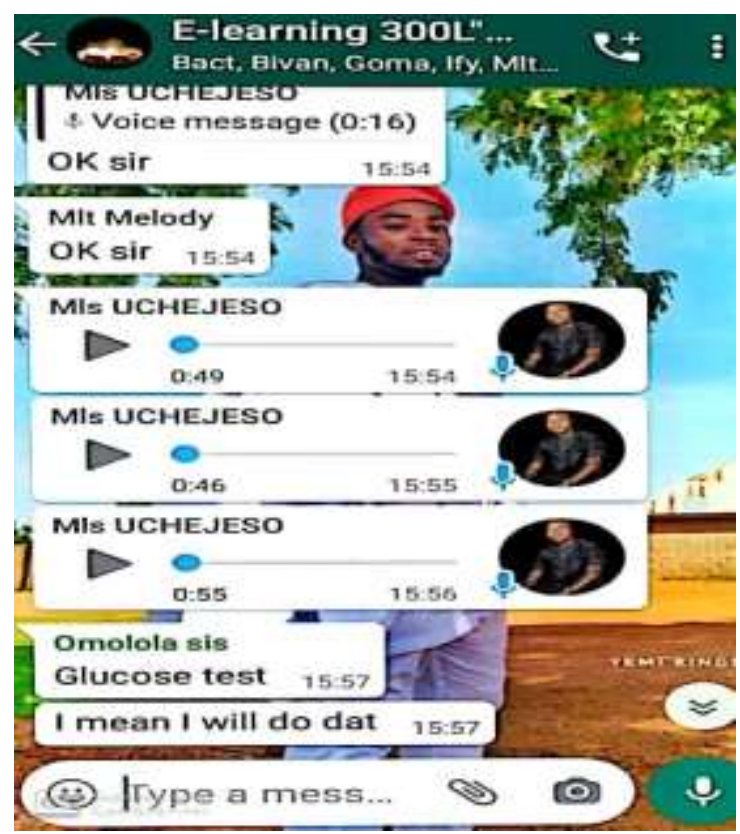

Figure 4 E-learning Voice Note

\section{Medical Laboratory Science as a Practical Based Study and Online learning}

Medical laboratory science comprises of vast collection of knowledge, skills and attitude of which the practitioner undergoing training would achieve following the learning objectives within each of their so called domains of learning to be considered competent to practice the profession. Once registered as a practitioner, continuing professional development (CPD) is required to maintain and further develop competence which is also a criteria for medical laboratory science council of Nigeria for annual license renewal. The acquisition of learning objectives is both in the undergraduate and postgraduate medical laboratory science education that can be achieved by a combination of modalities including didative teaching, apprenticeship, self-study and group learning. The recent development of ICT has allowed e-learning to attend a place in lecturers' toolbox (Choules, 2007) especially in medical laboratory science. A busy medical laboratory scientist can now search for an online database for the answer to his/her current laboratory diagnostic challenges with the appropriate technologies. This concept of e-learning formats have been used to support medical personnel in rural areas as well 
as in teaching hospitals who are less privileged in the latest research information.

Online learning in medical Laboratory science practice helps patient to access results if a test via email and other platform, and also for the health personnel to respond to patients questions. As computer and communication technologies are incorporated as teaching tools, traditional material and technologies that previously require a microscope and hard copy results are digitalized for study and easy use on a computer (White et al, 2001). Medical laboratory science is a broad profession with very wide practical areas in Chemical pathology, Haematology and blood transfusion science, Medical microbiology, Parasitology, Histopathology and cytogenetics, forensic science, etc. and various practical aspects can be demonstrated in short videos and uploaded to the online platforms of the students. In Federal School of medical laboratory science, Jos, students have expressed their easy and fast retention of practical procedures and methodologies using short videos than the bench or paper works. Therefore, in medical laboratory science which is a practical training profession, incorporation of demonstration of practical in online/virtual platforms such as zoom or short videos using You Tube and WhatsApp could go a long way to demonstrate practical while waiting for opportunity to do physical practical and medical laboratory postings for better assessment of practical performance.

\section{Role of Computer and Internet in Medical Laboratory Science Education}

Computer and internet in general play a very vital role in the medical Laboratory education. Easy access to information using the computer and internet has made the medical laboratory science more advanced and creative with new innovations.

Computer and internet are connected via different routes. They can be connected by coaxial cable, optical cable, telephone lines, radio waves, satellite, laser links etc. There are several ways in which computer and internet are connected by modem, other connection by so-called server host and nods.

Computer and Internet allows permanent data storage. The interconnected computers provide data transfer from different work stations. The combination of computer and internet helps data searching and processing, data availability at any moment of need, monitoring the patient's results, improve medical laboratory data, allows calculations and manipulation of test results and also helps student to access documentaries with ease. Computer in online teaching has provided collaboration, information network, reduced cost, convenience and good storage and use of information especially with education (Holmes and Reid, 2017, Al-Qahtani, 2019).

The experience in Federal school of medical laboratory science Jos revealed that less than $5 \%$ of the students have laptop but currently $100 \%$ can conveniently participate in online teaching platforms using WhatsApp and 70\% using Zoom. Our institution is a good evidence that there is a rise in online learning since the COVID-19 pandemic in Nigeria.

\section{Way Forward for E-learning and Teaching in Medical Laboratory Science Education}

The most important way in which implementation of online teaching and elearning programs can be successfully achieved is to include all stakeholders in medical laboratory training ranging from students, lecturers, institutions, regulatory agencies to collaborate and adopt new approaches currently available. For the elearning to succeed, stake holders must allow qualified and dedicated human resources, allocates financial resources, support of all stakeholders according to their needs. An institutional strategy is therefore required which facilitate the implementation of key online learning skills and the adoption of improved methodologies by institutions and regulatory bodies in medical laboratory science when implementing online learning (O'Doherty et al, 2018). Maintaining a positive attitude towards e-learning and being patient with the time consumed will bring forth achievement in medical laboratory education. E-learning and online teaching is easier and reliable. Online teaching creates teachers and learners individualization, relevance, convenience, selfassessment, independent learning and systematic educational approach among medical laboratory students. Though there may be poor technical knowledge, poor networks, power failure or other domestic distractions among Medical laboratory science students but the efficiency, conduciveness, wide coverage and international linkage, shall be an encouragement for online learning. It is therefore, very important to consider e-learning in medical laboratory science education based on appropriate relevance of courses based on curriculum which shall describe the quantity, 
difficulty, and length of teaching content. Impartation of knowledge based on language teaching speed with sufficient technical support and timely feedback should be inculcated in the e-learning processes. The assessment of highquality participation by the students is very important considering that the students are free. The training institution and the teachers' needs to put up some contingency plans in place for the cases of power supply, internet connectivity, data for teachers and students are very important in ensuring continuity and progress. This has been tried and noted in our institution and online teaching and e-learning which has never happened in the institution commenced and have been working effectively since $20^{\text {th }}$ April, 2020 till date. The research on the experience of the use of e-learning in medical laboratory science is ongoing and shall be shared in due course by way of publication.

\section{Conclusion}

Online teaching and learning has been the most highly and widely recommended forms of learning in the 21st century especially since the outbreak of coronavirus pandemic. It is a means of communication and learning in developed countries of which the developing countries like Nigeria should take advantage of it following the popularity given to it by the coronavirus pandemic or be left behind especially in a time like COVID-19 era and beyond.

For improving the educational sector of the medical laboratory science, online learning should be supported and encouraged by policy makers, training institutions and regulatory bodies in medical laboratory science.

Notably, the improvement in ICT from Desktops, to Laptops, palmtops and Android phones, has given rise to the online programmes such as e-business / ecommerce, e-governance and online / elearning.

Guidelines should be provided to ease access to online teaching learning in the medical laboratory environments ranging from colleges to universities. E-learning provide reusable and reliable content of information which is convenient for the learner as well as the trainer and medical laboratory science should not be an exception.

There is a sudden rise in online teaching and learning during COVID-19 pandemic which has been noted in the profession of medical laboratory science in Nigeria among the professionals and in the case of Federal School of Medical Laboratory Science in particular among the students under training.

\section{Acknowledgement}

The Authors acknowledge the Medical laboratory technician, MLT Ibrahim Asiya for her typesetting and minor contribution to the chapter.

\section{References}

Al-Qahtani, M. H. (2019). Teachers' and Students' Perceptions of virtual Classes and the effectiveness of Virtual Classes in Enhancing Communication Skills. Arab World English Journal, Special Issue: The Dynamics of EFL in Saudi Arabia. 223-240. DOI: https://dx.doi.org/10.24093/awej/efl1.16

Bao, W. (2020). COVID-19 and online teaching in higher education: A case study of Peking University.Human behavior and Emerging Technology.

2:113-115.

DOI:10.1002/hbe2.191

Bodhare, T. (2020). E-learning: A key to sustain learning during COVID-19 pandemic. Int $\mathrm{J}$ Health Allied Sci. 9:298-300. DOI:10.4103/ijhas.IJHAS_104_20

Choules, A.P. (2007). The use of E-learning in medical education: A review of the current situation. Post Grad Med J; 83:212-216.

Dias, M.O., Lopes, R.A., Teles, A.C. (2020). Will virtual Replace classroom Teaching? Lessons from Virtual Classes Via Zoom in the Times of COVID-19. Journal of Advances in Education and Philosophy, 4(5):208-213. DOI:10.36348/jaep.2020.v04i05.004

Etukudoh, N.S., Ejinaka, R.O., Olowu, F.A., Obeta, M.U., Adebowale, O.M., Udoudoh, M. P. (2020). Coronavirus (COVID-19); Review from a Nigerian Perspective. 9(1). AJBSR.MS.ID.001347.

FAO (2011). E-learning methodologies: A guide for designing and developing e-learning courses. Rome.

FMoH. (2020) First case of Coronavirus disease confirmed in Nigeria, Press Release, 27th February, 2020 Accessed on February 28, $2020.2 \quad$ From https://ncdc.gov.ng/news/227/first-case-ofcorona-virus-disease-confirmed-in-nigeria 
Frehywort, S., Voiudes, Y., Talib, Z., Milchail, N., Rose, H., Wohltjen, H., Bedada, S., Korhumel, K., Abdel, K., Koumare, A.K. and Scott, J. (2013): E-learning in medical education in resource constrained low and middle income countries. Human Resources for Health, 11:4.

Izet, M. (2008). E-learning as New Method of Medical Education. AIM: 16(2) 102-117 doi:10.5455/aim.2008.16.102-117.

Kimberly, C.H., Kuanchin C., David C.Y. (2004). Distance learning, virtual classrooms, and teaching pedagogy in the Internet environment. Elsevier. Technology in Society 26 (2004) 585-598.

Holmes, C. M., \& Reid, C. (2017). A comparison study of and online learning outcomes for a research methods course. The journal of counsellor preparation and supervision, 9(2).

Murillo, D. D., Raphael, D.A.L., Andre, C. T. (2020). Will virtual Replace classroom Teaching? Lessons from Virtual Classes Via Zoom in the Times of COVID-19. Journal of Advance in Education and philosophy; 4(5):208-213.

Obeta, M.U., Maduka, M.K. \& Ejinaka, O.R. (2020a). Medical Laboratory Science; the Distortion of Nomenclature across the Globe. New Zealand Journal of Med. Lab. Science. Pg 52

Obeta, M.U., Maduka, K.M., Ofor, I.B., Ofojekwu, N.M. (2019). Improving Quality and Cost Diminution in Modern Healthcare Delivery: The Role of the Medical Laboratory Scientists in Nigeria. International Journal of
Business and Management Invention (IJBMI), 08(03):08-19. www.ijbmi.org

Obeta, M.U., Ejinaka, R.O., Ofor, I.B., Ikeagwulonu, R.C., Agbo. E.C., and Abara, U.S. (2020b). Nigerian COVID-19 (Coronavirus) Patients Update, the Realities with Medical Laboratory Diagnostic Sites. American Journal of Epidemiology and Infectious Disease, 8(1):13-15. doi: 10.12691/ajeid-8-1-3.

Obeta, M.U., Ikeagwulonu, R.C., Ejinaka, R.O. (2020c). Covid-19: The Stimulus for Virtual Learning in Medical Laboratory Science. J.Bio.Innov $\quad 9(5)$ : $\quad 812-820$. https://doi.org/10.46344/JBINO

O'Doherty, D, Dromey, M, Lougheed, J, Hannigan, A, Last, J. and Deirdre, M.D. (2018).Barriers and solutions to online learning in medical education - an integrative review. BMC Medical Education. 18:130 https://doi.org/10.1186/s12909-018-1240-0

Omoregbe, N.A., Azeta A.A., Osagie, U.B., Agarana, M.C. (2015). Design and implementation of a Virtual Classroom System. Proceedings of ICERI2015 Conference 16th-18th November 2015, Seville, Spain Pp 1179-1181.

Shrivastava, S.R. and Shrivastava, P.S (2019). Need of E-learning in medical education and strategies for its implementation in medical colleges in India. Indian Journal of Health Sciences and Biomedical Research; 12:2645.

White, L.E., Krousel-Wood, M.A., Mather, F. (2001). Technology meets healthcare: Distance learning and telehealth. The Ochsner Journal. 3:22-29. 